\title{
Ossification anomalies-psychomotor developmental delay syndrome
}

INSERM

\section{Source}

INSERM. (1999). Orphanet: an online rare disease and orphan drug data base.

Ossification anomalies-psychomotor developmental delay syndrome. ORPHA:73230

Ossification anomalies-psychomotor developmental delay syndrome is characterised by hypomineralisation of the cranial bones, thoracic dystrophy, hypotonia, and abnormal and slender long bones due to an alteration in remodelling during ossification. 